\title{
OS DIFERENCIAIS DE SALÁRIO POR GÊNERO NO RIO GRANDE DO SUL: UMA APLICAÇÃO DO MODELO DE HECKMAN E DA DECOMPOSIÇÃO DE OAXACA-BLINDER
}

\section{THE DIFFERENTIALS OF WAGE BY GENDER IN RIO GRANDE DO SUL: AN APPLICATION OF THE HECKMAN MODEL AND OAXACA-BLINDER DECOMPOSITION}

\author{
Rafael Mesquita Pereira \\ Universidade Federal do Rio Grande - Rio Grande - RS - Brasil \\ Cristiano Aguiar de Oliveira \\ Universidade Federal do Rio Grande - Rio Grande - RS - Brasil
}

\begin{abstract}
Resumo: O objetivo deste artigo é analisar o diferencial de salários do trabalho entre homens e mulheres no Rio Grande do Sul. Para tanto, a partir da base de dados do Censo 2010 Instituto Brasileiro de Geografia e Estatística - IBGE, é estimada uma equação do tipo minceriana com correção para autoseleção, com o intuito de avaliar os fatores que são determinantes dos salários dos indivíduos. Os resultados mostram que a educação tem papel fundamental na determinação dos salários. Além disso, a desagregação da variável escolaridade permite verificar os retornos nos salários gerados por cada nível de qualificação educacional. Após, realiza-se a decomposição do diferencial de salários por gênero a partir do procedimento de Oaxaca-Blinder. A decomposição deste diferencial constata que existe discriminação estatística de cerca de $15 \%$ nos salários contra as mulheres no estado, tanto intersetorialmente quanto intrasetorialmente. Além disso, a discriminação intrasetorial apresentou maior peso no diferencial de rendimentos que a discriminação intersetorial.
\end{abstract}

Palavras-chave: Equação de salários. Decomposição de Oaxaca-Blinder. Discriminação.

Abstract: The objective of this paper is to analyze the difference in wages between men and women in Rio Grande do Sul Therefore, from the 2010 Census database. - IBGE, it is estimated an mincerian equation with correction for self-selection in order to assess the factors that are determining the wages of individuals. The results show that education has a fundamental role in determining wage. In addition, the disaggregation of schooling variable allows to check the returns on the wage generated by each level of educational qualification. After it the decomposition of the gender wage differential is estimated using the Oaxaca-Blinder procedure. The decomposition of this differential shows that there is statistical discrimination against women in the state of $15 \%$ in their wages, both between activity sectors and within sectors. Furthermore, within sector discrimination had higher weight in the differential than between discrimination.

Keywords: Wages equation. Oaxaca-Blinder Decomposition. Discrimination.

\section{Introdução}

Um dos temas mais importantes no estudo da economia do trabalho é o que considera o conjunto de habilidades mercadológicas dos trabalhadores como uma forma de capital. Isso exige uma variedade de investimentos por parte dos trabalhadores na busca por sua acumulação. Segundo Acemoglu e Autor (2012), capital humano corresponde a qualquer estoque de conhecimento ou características que o trabalhador possui e que contribui para a sua produtividade. 
Na visão de Becker (1975), o capital humano aumenta a produtividade do trabalhador em todas as funções, embora possivelmente de forma distinta em diferentes tarefas. Já Gardner (1983) caracteriza as habilidades mentais versus físicas como habilidades diferentes, ou seja, talvez muitas personalidades geniais não teriam o mesmo desempenho que obtêm em suas áreas desempenhando outras atividades. Para Schultz (1961), o capital humano é visto mais como uma capacidade de adaptação, dado que os ambientes de trabalho sofrem mudanças constantemente. Bowles e Gintis (1975) caracterizam o capital humano como a capacidade de trabalhar em organizações, obedecer a ordens, adaptar a vida a uma sociedade hierárquica/capitalista.

Não obstante a essas análises, Acemoglu e Autor (2012) também destacam que as diferenças podem estar nas diferentes fontes de capital humano. A habilidade inata é uma dessas fontes, uma vez que os trabalhadores podem ter diferentes montantes de capital humano oriundas de algum componente genético, tal como o Quociente de Inteligência - QI, que os diferencia. O nível de escolaridade, foco de muitas pesquisas, também é uma fonte de diferenças de capital humano. No entanto, sua análise é muito mais informativa, visto que as diferenças entre níveis de escolaridade podem estar nas diferentes formas de investimento em escolaridade, como por exemplo, pagar uma escola particular ou usufruir o ensino público, o que, em tese, tem menor qualidade que o primeiro (ACEMOGLU; AUTOR, 2012). Pode-se incluir também, nessas fontes de diferenças de capital humano, o treinamento, que se caracteriza por ser adquirido após concluída a vida escolar do trabalhador, onde ele se especializa em determinado procedimento laboral que o qualifica a desempenhar atividades específicas dentro de um setor.

Para Borjas (2005), as pessoas adquirem a maior parte de seu capital humano na escola e em programas formais e informais de treinamento dentro das empresas, os chamados on-the-job trainings, que se caracterizam por serem treinamentos disponibilizados pelas empresas para aperfeiçoar as habilidades de seus empregados. Conforme Schultz (1961) e Becker (1975) ratificam, à medida que as despesas para melhorar as capacidades (habilidades) também aumentarem a produtividade, os resultados trarão taxas de retorno positivas a tais investimentos. $\mathrm{E}$, por conseguinte, gerarão um círculo virtuoso: o aumento da produtividade resultará em um aumento de salário que, por sua vez, estimulará o trabalhador a investir cada vez mais em sua capacitação.

Cabe ressaltar a diferença entre on-the-job training e o modelo learningby-doing proposto por Arrow (1962). O primeiro realiza-se dentro da empresa, onde o trabalhador recebe treinamento para realizar atividades gerais ou específicas no seu ambiente de trabalho. Já o segundo diz respeito, como a própria denominação remete, ao aprender-fazendo, ou seja, quando a acumulação de conhecimento ocorre, em parte, não por um esforço deliberado, mas como parte do efeito da atividade econômica convencional exercida pelo trabalhador (ARROW, 1962).

Adicionalmente, Becker (1975) sugere que muitos trabalhadores aumentam sua produtividade aprendendo novas habilidades e aperfeiçoando as antigas enquanto estão trabalhando. Acemoglu e Autor (2012) acrescentam destacando que a troca de ideias entre os trabalhadores aumenta a produtividade das 
empresas, as chamadas externalidades não pecuniárias de capital humano (este tipo de externalidade também é conhecida como externalidade Marshalliana).

Analisando a agregação de capital humano pela ótica dos níveis de qualificação, Borjas (2005) ressalta que as habilidades adquiridas na escola tornam-se cada vez mais importantes para o aumento do estoque de conhecimento dos indivíduos. Nesse contexto, assume-se que os trabalhadores adquirem níveis de educação que maximizem o valor presente dos seus rendimentos ao longo de suas vidas. Assim, a educação e outras formas de treinamento são apenas valorizadas porque aumentam os salários e, portanto, desconsidera-se o fato de que uma formação em ensino superior afeta, também, a utilidade dos indivíduos em muitos outros caminhos.

Ademais, Acemoglu e Autor (2012) caracterizam a educação como um "bem" de consumo. Dessa forma, acreditam que a renda (restrição orçamentária) dos pais é uma variável relevante na obtenção de capital humano. Além disso, constatam que a possibilidade de aquisição de crédito para o investimento na educação é uma variável não observada que influencia sobremaneira no crescimento do nível de escolaridade dos indivíduos.

Como se pode observar, há, na análise do capital humano, uma ligação entre os salários dos indivíduos e seus níveis de escolaridade. É senso comum que, quanto maior o nível de escolaridade do trabalhador, maiores serão os salários que estes trabalhadores auferirão.

Para Borjas (2005), a combinação salário-escolaridade tem três propriedades importantes. A primeira explica que trabalhadores que possuem mais educação devem ganhar mais enquanto as decisões educacionais forem motivadas apenas pelo ganho financeiro. Dessa forma, os empregadores, por outro lado, para atrair trabalhadores com níveis de escolaridade elevados, devem compensar estes últimos pelos custos originados na aquisição de maiores níveis de educação. A segunda relação diz respeito à empírica causalidade direta entre escolaridade e salários, ou seja, espera-se que o aumento nos salários seja diretamente relacionado ao nível de escolaridade do trabalhador. Para tal análise, é importante ressaltar a taxa marginal de retorno à escolaridade, que se refere à mudança percentual nos salários resultante de um ano a mais de escolaridade. A terceira e última propriedade refere-se ao possível formato côncavo da curva saláriosescolaridade. Em outras palavras, isso significa que essa curva cresce a taxas decrescentes. Sendo assim, cada ano de escolaridade a mais irá gerar incrementos cada vez menores de conhecimento, diminuindo os rendimentos adicionais em comparação com os anos de escolaridade anteriores. Tal propriedade é evidenciada empiricamente por Psacharapoulos (1985) e Resende e Wyllie (2006), que ratificam a afirmação de que o percentual dos retornos à educação vai diminuindo à medida que o nível de escolaridade aumenta.

Outro ponto interessante a respeito do investimento em capital humano é abordado por Schultz (1961). O autor considera as migrações da zona rural para a urbana como uma forma de investimento em capital humano. Segundo ele, o gasto com a migração interna de trabalhadores é uma forma de investimento, visto que estes trabalhadores podem rumar para regiões urbanas onde haja maiores oportunidades de trabalho. Acrescenta, ainda, que pessoas jovens podem esperar mais retorno de seus investimentos de migração do que velhas pessoas, pois acredita que pessoas jovens têm mais anos de trabalho à frente que velhos 
trabalhadores. Além disso, ressalta que os jovens possuem uma vantagem competitiva com relação aos velhos trabalhadores, visto que os primeiros, segundo ele, possuem mais anos de escolaridade que os velhos trabalhadores.

Dessa forma, após a fundamentação teórica desenvolvida acerca das fontes, possibilidades e formas de aquisição de capital humano, torna-se necessário desenvolver métodos que auxiliem a identificar uma relação empírica entre os salários e os níveis de capital de humano dos indivíduos.

Segundo Acemoglu e Autor (2012), existem três possibilidades no conceito estrutural da distribuição empírica dos salários: a primeira refere-se aos diferenciais de compensação, em que um trabalhador pode receber menos dinheiro porque realizou menos esforço. A segunda possibilidade diz respeito às imperfeições no mercado de trabalho, pois dois trabalhadores com o mesmo capital humano podem receber diferentes salários, porque seus trabalhos diferem em termos de produtividade, ou seja, um combina altos níveis de produtividade e trabalho e outro, baixos níveis. $\mathrm{E}$, por fim, a terceira possibilidade refere-se à diferenciação por gênero ou raça, em que os empregadores podem pagar menores salários a um trabalhador devido aos seus preconceitos com relação ao sexo ou raça destes últimos.

Nesse contexto, Mincer (1974) desenvolveu a função de salários de capital humano empiricamente, na qual incluiu, juntamente com a variável de escolaridade, a variável experiência dos trabalhadores. Esta última é medida por meio da suposição de que se a experiência do trabalhador é contínua e começa imediatamente a partir da conclusão da escola. Sua experiência, então, seria igual a sua idade corrente subtraída da idade que o trabalhador entrou na escola. Assim, constatou que o logaritmo dos salários era obtido por meio da uma equação na qual apresenta uma variável que representasse os anos de experiência do trabalhador no mercado de trabalho, seu número de anos de escolaridade e a experiência na forma quadrática, para capturar a concavidade da relação idadesalários, ou seja, os retornos de experiência nos salários. Além dessas, acrescentase um vetor contendo outras variáveis, que visam captar outras características dos indivíduos que afetam seus rendimentos (raça, gênero, etc...).

Conforme ressalta Borjas (2005), a equação de salários proposta por Mincer (1974) demonstra que o coeficiente da variável escolaridade estima o aumento percentual nos ganhos resultante de um ano adicional de escolaridade e é normalmente interpretado como a taxa de retorno à escolaridade. Entretanto, essa interpretação é correta apenas quando os trabalhadores não diferem em suas habilidades não observadas. Os coeficientes da experiência e experiência elevada ao quadrado estimam a taxa de crescimento nos salários, resultante da adição de um ano de experiência no mercado de trabalho e são tipicamente interpretados como medida de impacto dos on-the-job trainings no portfólio do capital humano dos trabalhadores.

Um trabalho pioneiro no Brasil na avaliação dos retornos à educação nos rendimentos foi o desenvolvido por Senna (1976), no qual o autor realizou uma comparação dos retornos, tanto com respeito à educação quanto à experiência, obtidos por trabalhadores empregados nos setores público e privado. Ele constatou que no setor privado os indivíduos com mais experiência no trabalho tendem a ser aqueles que detêm maiores níveis de escolaridade, e, no setor público, os indivíduos com maiores níveis de educação tendem a ser os que possuem menores 
níveis de experiência no trabalho. Após, uma série de trabalhos como o de Ramos (1991), Kassouf (1994), Barros e Ramos (1994), Menezes-Filho, Fernandes e Picchetti (2000), Sachsida, Loureiro e Mendonça (2004), Resende e Wyllie (2006), Barbosa Filho e Pessôa (2008), Salvato e Silva (2008) estimaram a relação escolaridade-salários de diferentes formas para o Brasil e identificaram a relação positiva entre estas variáveis.

Dentre esses, destaca-se o trabalho de Sachsida, Loureiro e Mendonça (2004), que buscaram ressaltar as possíveis fontes de viés nas equações mincerianas estimadas por Mínimos Quadrados Ordinários - MQO. De acordo com os autores, tais fontes podem ser decorrentes da existência de salário de reserva no mercado de trabalho, endogeneidade na decisão por estudo e existência de "viés de habilidade" em tais estimações. Também, ressalta-se a contribuição de Kassouf (1994) ao apresentar uma nova metodologia para a estimação da equação rendimentos, em se tratando de literatura nacional, e que até hoje é utilizada como padrão. Segundo a autora, uma vez que grande parte dos adultos, em uma amostra, não participa do mercado de trabalho, a simples estimação utilizando-se da técnica de MQO produziria estimadores tendenciosos. Assim, estimou equações de participação no mercado de trabalho e de determinação dos salários para homens e mulheres (Modelo de Heckman), com o objetivo de comparar os resultados deste procedimento com o método tradicional de estimação (MQO).

Entretanto, quando são estimadas equações de salários distintas para homens e mulheres, tem-se constatado uma situação recorrente: homens ganham, em média, maiores salários que as mulheres no mercado de trabalho. Esse fato tem chamado a atenção dos pesquisadores que estudam os diferenciais de salários, pois indivíduos igualmente produtivos estão sendo diferentemente avaliados no mercado de trabalho com base em atributos não produtivos, caracterizando, assim, a existência de discriminação neste mercado (CAVALIERI; FERNANDES, 1998).

A primeira contribuição para análise das desigualdades no mercado de trabalho brasileiro foi realizada por Langoni (1973). O autor, com informações censitárias, procurou descrever o perfil da distribuição pessoal de renda em 1970 (comparando com a de 1960), com o objetivo de analisar o processo de geração e revelação das desigualdades de renda no mercado de trabalho por meio de diferenciais de salários associados ao tipo de trabalhador e ao posto de trabalho. Também procurou investigar as relações entre diferenciais de salário e nível educacional, idade, gênero, setor de atividade e região de residência. Dessa forma, tentou mostrar que essas características são determinantes nos diferenciais de salários, destacando que as disparidades educacionais existentes entre os trabalhadores constituem-se no principal fator determinante desses diferenciais (COELHO; CORSEUIL, 2002).

Após, trabalhos como os de Camargo e Serrano (1983), Barros, Ramos e Santos (1995), Queiroz e Moreira (2009) e Freisleben e Bezerra (2011) constataram a existência de discriminação salarial por gênero no mercado de trabalho brasileiro. Adicionalmente, Cavalieri e Fernandes (1998), Leme e Wajnman (2000a), Giuberti e Menezes-Filho (2005), Cambota e Marinho (2007) e Scorzafave e Pazello (2007) constataram que, além da existência de discriminação por gênero, se as mulheres fossem remuneradas por seus níveis de escolaridade no mercado de trabalho receberiam mais que os homens, evidenciando que o 
elemento discriminatório tem mais peso na determinação dos salários que os atributos produtivos dos indivíduos.

Diante do exposto, o objetivo deste artigo é identificar a existência de diferencial de salários entre homens e mulheres no Rio Grande do Sul. Para tanto, inicialmente, será estimada uma equação de salários tal como proposta por Mincer (1974), com correção para viés de autoseleção (Modelo de Heckman). Após, realizar-se-á a decomposição do diferencial dos salários por gênero, usando como estratégia empírica o procedimento desenvolvido por Oaxaca (1973) e Blinder (1973). Este último visa, também, constatar se este diferencial está atrelado a características produtivas dos indivíduos ou a componentes que caracterizam a existência de discriminação salarial entre gêneros.

A base de dados que será utilizada é o Censo 2010, realizado pelo IBGE. O diferencial em utilizar essa base dados está no número de observações disponíveis - aproximadamente 1.300.000 somente para o Estado do Rio Grande do Sul -, enquanto que a Pesquisa Nacional por Amostragem de Domicílios - PNAD possui, aproximadamente, apenas 340.000 observações referentes ao Brasil e a seus estados.

Este artigo pretende proporcionar um guia para estudos referentes ao mercado de trabalho no estado, uma vez que a utilização do Censo Demográfico permite uma estimação bem próxima dos parâmetros populacionais. Além disso, será apresentado um panorama geral do mercado de trabalho local, de modo a contribuir com o conhecimento de suas características principais e, também, colaborar com o entendimento de possíveis peculiaridades com relação à alocação de homens e mulheres neste mercado.

Além desta introdução, o artigo está organizado da seguinte maneira. A segunda seção refere-se à metodologia. A terceira seção apresenta análise descritiva dos dados. A quarta seção é referente aos resultados obtidos por meio da estimação da equação de salários para o Rio Grande do Sul e da decomposição do diferencial de salários entre os gêneros. Por fim, são apresentadas as conclusões do artigo.

\section{Metodologia}

\subsection{Modelo de Heckman em dois estágios}

Para solucionar o problema de viés de seleção das informações, Heckman (1979) propôs um modelo de duas equações, incluindo características pessoais dos indivíduos, avaliando os fatores que determinam a participação ou não destes no mercado de trabalho para, logo após, estimar uma segunda equação referente aos salários destes indivíduos que participam do mercado mencionado.

Segundo Heckman (1979), o viés de seleção de amostra pode surgir, na prática, por duas razões. Primeiro, pode haver autoseleção por parte dos indivíduos ou unidades de dados que estão sendo investigados. Em segundo lugar, as decisões de seleção de amostra por analistas ou processadores de dados funcionam praticamente da mesma maneira que uma autoseleção. Sendo assim, o Modelo de Seleção Amostral desenvolvido por Heckman (1979) é considerado o mais adequado para estimar as equações de salários do tipo mincerianas, pois 
corrige o problema de viés de seleção amostral que a estimação por MQO normalmente apresenta.

O modelo de seleção amostral proposto por Heckman (1979) foi desenvolvido dentro do contexto da equação de salários: $W_{i}=x_{i}^{\prime} \beta+\varepsilon_{i}$

onde $W_{i}$ é o salário, $x_{i}^{\prime}$ representa as variáveis observadas relacionadas à produtividade do i-ésimo indivíduo e $\varepsilon_{i}$ é um termo de erro. Wé observado apenas para os trabalhadores, ou seja, apenas as pessoas que recebem salário pelo trabalho. Segundo Cameron e Trivedi (2005), este modelo de seleção amostral bivariado é representado da seguinte forma:

que resultará na seguinte equação:

$$
W_{1 i}=\left\{\begin{array}{l}
1 \text { se } W_{1 i}^{*}>0 \\
0 \text { se } W_{1 i}^{*} \leq 0
\end{array}\right.
$$

$$
W_{2 i}=\left\{\begin{array}{c}
W_{2 i}^{*} \text { se } W_{1 i}^{*}>0 \\
\text { se } W_{1 i}^{*} \leq 0
\end{array}\right.
$$

Ainda, de acordo com Cameron e Trivedi (2005), esse modelo especifica que $W_{2}$ é observado quando $W_{1}^{*}>0$, de modo que $W_{2}$ não precisa ter qualquer valor significativo quando $W_{1}^{*} \leq 0$. Dessa forma, para um $W_{2}$ positivo, a densidade observada é $f^{*}\left(W_{2}^{*} \mid W_{1}^{*}>0\right) x \operatorname{Pr}\left[W_{1}^{*}>0\right]$. Então, a equação de seleção tem a seguinte função de verossimilhança:

$$
L=\prod_{i=1}^{n}\left\{\operatorname{Pr}\left[W_{1 i}^{*} \leq 0\right]\right\}^{1-W_{1 i}}\left\{\mathrm{f}\left(W_{2}^{*} \mid W_{1 i}^{*}>0\right) x \operatorname{Pr}\left[W_{1 i}^{*}>0\right]\right\}^{W_{1 i}}(2)
$$

onde o primeiro termo é a contribuição discreta quando $W_{1 i}^{*} \leq 0$, uma vez que $W_{1 i}=0$, e o segundo termo é a contribuição contínua quando $W_{1 i}^{*}>0$.

Realizada esta primeira etapa, parte-se para a estimação, de fato, da equação de salários, utilizando o método de Mínimos Quadrados Ordinários (MQO). Conforme destacam Cirino e Lima (2010), esta equação é formulada a partir da teoria do capital humano, incluindo algumas outras variáveis com o intuito de controlar as diferenças de salários derivadas de setores de atividades, posição e tipo de ocupação, além da inserção no mercado de trabalho. Assim, torna-se possível obter uma medida mais adequada das diferenças de salários entre os gêneros, objetivo central deste trabalho.

De acordo com Cameron e Trivedi (2005), o procedimento de Heckman em dois estágios aumenta a regressão por MQOs por meio de uma estimativa do regressor omitido $\lambda_{i}\left(z_{i}^{\prime} \gamma\right)$. Assim, usando os valores positivos de $W_{2}$, a estimativa por MQO do modelo é: $W_{2 i}=\boldsymbol{x}_{2 i}^{\prime} \boldsymbol{\beta}_{2}+\sigma_{12} \lambda\left(\boldsymbol{x}_{1 i}^{\prime} \widehat{\boldsymbol{\beta}}_{1}\right)+\varepsilon_{i}(3)$

onde $\varepsilon$ é um termo de erro, $\widehat{\boldsymbol{\beta}}_{1}$ é obtido por meio do primeiro estágio da regressão Probit de $W_{1}$ em $x_{1}$, uma vez que $\operatorname{Pr}\left[W_{1 i}^{*}>0\right]=\varphi\left(\boldsymbol{x}_{1}^{\prime} \boldsymbol{\beta}_{1}\right)$, e $\lambda\left(\boldsymbol{x}_{1}^{\prime} \widehat{\boldsymbol{\beta}}_{1}\right)=$ $\varphi\left(\boldsymbol{x}_{1}^{\prime} \widehat{\boldsymbol{\beta}}_{1}\right) / \Phi\left(\boldsymbol{x}_{1}^{\prime} \widehat{\boldsymbol{\beta}}_{1}\right)$ é o inverso da razão de Mills estimada. Essa regressão não fornece diretamente uma estimativa de $\sigma_{2}^{2}$, mas a fórmula da variância truncada ${ }^{1}$ leva a estimar $\hat{\sigma}_{2}^{2}=N^{-1} \sum_{i}\left[\hat{\varepsilon}_{i}^{2}+\hat{\sigma}_{12}^{2} \hat{\lambda}_{i}\left(\boldsymbol{x}_{1}^{\prime} \widehat{\boldsymbol{\beta}}_{1}+\hat{\lambda}_{i}\right)\right]$, onde $\hat{\varepsilon}_{i}$ é o resíduo de MQO a partir da equação $W_{2 i}=\boldsymbol{x}_{2 i}^{\prime} \boldsymbol{\beta}_{2}+\sigma_{12} \lambda\left(\boldsymbol{x}_{1 i}^{\prime} \widehat{\boldsymbol{\beta}}_{1}\right)+\varepsilon_{i}$ e $\hat{\lambda}_{i}=\lambda\left(\boldsymbol{x}_{1 i}^{\prime} \widehat{\boldsymbol{\beta}}_{1}\right)$. A correlação entre os dois erros ${ }^{2}$ pode, em seguida, ser estimada por meio de $\hat{\rho}=\hat{\sigma}_{12} / \hat{\sigma}_{2}$.

${ }^{1} V\left[W_{2} \mid \boldsymbol{X} . W_{1}^{*}>0\right]=\sigma_{2}^{2}-\sigma_{12}^{2} \lambda\left(\boldsymbol{x}_{1}^{\prime} \beta_{1}\right)\left(\boldsymbol{x}_{1}^{\prime} \beta_{1}+\lambda\left(\boldsymbol{x}_{1}^{\prime} \beta_{1}\right)\right.$.

${ }^{2}$ De acordo com Cameron e Trivedi (2005), a estimação por máxima verossimilhança é simples dado a abordagem adicional na qual erros correlacionados são conjuntamente normalmente 
Dessa forma, de acordo com Cameron e Trivedi (2005), o estimador de $\boldsymbol{\beta}_{2}$ é consistente. Apesar de uma perda de eficiência em comparação com o estimador de máxima verossimilhança sob normalidade conjunta dos erros, os quais podem ser bastante grandes, este estimador é muito popular pelas seguintes razões: é simples de implementar, sua abordagem é aplicável a uma gama de modelos de seleção e o estimador requer suposições distribucionais mais fracas do que a normalidade conjunta de $\varepsilon_{1}$ e $\varepsilon_{2}$.

\subsection{Decomposição de Oaxaca-Blinder}

A decomposição de Oaxaca (1973) e Blinder (1973) pode ser utilizada para quantificar as contribuições de diferenças nas características de produtividade e a discriminação via diferenciais de salários. Sejam dois grupos: $A$ (homens) e $B$ (mulheres), uma variável $Y$ (log dos rendimentos) e um conjunto de indicadores de capital humano tais como educação e experiência no trabalho como preditores (JANN, 2008). A partir dessa estrutura, busca-se mensurar a magnitude da diferença média do salário, representada da seguinte forma: $R=E\left(Y_{A}\right)-E\left(Y_{B}\right)(4)$

onde $E(Y)$ representa o valor esperado da variável salário, a qual é contabilizada por meio das diferenças entre grupos nos preditores, baseada no seguinte modelo linear: $Y_{l}=X_{l}^{\prime} \beta_{l}+\varepsilon_{l}, E\left(\varepsilon_{l}\right)=0, l \in\{A$ e $B\}(5)$

no qual $X$ é um vetor contendo os preditores e uma constante. $\beta$ contém os parâmetros de inclinação e o intercepto, e $\varepsilon$ é o termo de erro. A diferença média de salários pode ser expressa como a diferença na predição linear na média dos regressores do grupo específico, representado abaixo como:

$R=E\left(Y_{A}\right)-E\left(Y_{B}\right)=E\left(X_{A}\right)^{\prime} \beta_{A}-E\left(X_{B}\right)^{\prime} \beta_{B}(6)$

uma vez que $E\left(Y_{l}\right)=E\left(X_{l}^{\prime} \beta_{l}+\varepsilon_{l}\right)=E\left(X_{l}^{\prime} \beta_{l}\right)+E\left(\varepsilon_{l}\right)=E\left(X_{l}\right)^{\prime} \beta_{l}, \quad E\left(\beta_{l}\right)=\beta_{l}$ e $E\left(\varepsilon_{l}\right)=0$ por suposição.

Conforme Jann (2008), uma decomposição alternativa que é proeminente na literatura de discriminação resulta do conceito de que há algum vetor de coeficientes não discriminatórios que deve ser usado para determinar a contribuição de diferenças nos preditores. A diferença de salários pode, então, ser escrita da seguinte forma:

$$
R=\left[E\left(X_{A}\right) E\left(X_{B}\right)\right]^{\prime} \beta^{*}+\left[E\left(X_{A}\right)^{\prime}\left(\beta_{A}-\beta^{*}\right)+E\left(X_{B}\right)^{\prime}\left(\beta_{B}-\beta^{*}\right)\right](7)
$$

A equação (7) é conhecida como decomposição "two-fold", que pode ser expressa como $R=Q+U$, em que o primeiro componente $Q=\left[E\left(X_{A}\right) E\left(X_{B}\right)\right]^{\prime} \beta^{*}$ é a parte do diferencial de salário que é "explicado" pelas diferenças entre grupos nos preditores (efeito quantidade) e o segundo componente $U=\left[E\left(X_{A}\right)^{\prime}\left(\beta_{A}-\right.\right.$ $\left.\beta^{*}\right)+E\left(X_{B}\right)^{\prime}\left(\beta_{B}-\beta^{*}\right)$ ] é a parte "não explicada". Esta última é usualmente atribuída à discriminação, mas é importante reconhecer que ela também captura todos os efeitos potenciais de diferenças em variáveis não observadas.

A parte "não explicada" em (7) é, por vezes, ainda mais decomposta. Deixando $\beta_{A}=\beta^{*}+\delta_{A}$ e $\beta_{B}=\beta^{*}+\delta_{B}$ com $\delta_{A}$ e $\delta_{B}$ como vetores de parâmetros

distribuídos e homocedásticos, com $\left[\begin{array}{l}\varepsilon_{1} \\ \varepsilon_{2}\end{array}\right] \sim N\left[\begin{array}{l}0 \\ 0\end{array}\right] \cdot\left[\begin{array}{cc}1 & \sigma_{12} \\ \sigma_{12} & \sigma_{2}^{2}\end{array}\right]$. Como se trata de um modelo Probit, a normalização $\sigma_{1}^{2}=1$ é apenas utilizada desde que $W_{1}^{*}$ seja observado. 
de discriminação entre grupos específicos (discriminação positiva ou negativa, dependendo do sinal), $U$ pode ser expresso como: $U=\left[E\left(X_{A}\right)^{\prime} \delta_{A}-E\left(X_{B}\right)^{\prime} \delta_{B}\right](8)$ Isto é, o componente não explicado do diferencial pode ser subdividido em uma parte $U_{A}=E\left(X_{A}\right)^{\prime} \delta_{A}$, à qual mede a discriminação em favor do grupo $\mathrm{A}$, e uma parte $U_{B}=E\left(X_{B}\right)^{\prime} \delta_{B}$, que quantifica a discriminação contra o grupo B. Entretanto, essa interpretação depende da suposição de que não existem preditores relevantes não observados.

A determinação dos componentes da decomposição "two-fold" é mais complexa porque uma estimativa para o vetor de coeficientes não discriminatórios desconhecidos $\beta^{*}$ é necessária. Por exemplo, pode haver razões para assumir que a discriminação é direcionada para um dos grupos apenas, de modo que $\beta^{*}=\beta_{A}$ ou $\beta^{*}=\beta_{B}$. Assumindo que o grupo $\mathrm{A}$ representa os homens e o grupo $\mathrm{B}$ as mulheres, se, por exemplo, a discriminação de salário é apenas direcionada contra as mulheres e não existe discriminação (positiva) para homens, deverá ser utilizado $\hat{\beta}_{A}$ como uma estimativa para $\beta^{*}$ e computar a decomposição (7) como:

$$
\hat{R}=\left(\bar{X}_{A}-\bar{X}_{B}\right)^{\prime} \hat{\beta}_{A}+\bar{X}_{B}^{\prime}\left(\hat{\beta}_{A}-\hat{\beta}_{B}\right)(9)
$$

Similarmente, se não existe discriminação de mulheres, mas apenas (positiva) discriminação de homens, a decomposição é: $\hat{R}=\left(\bar{X}_{A}-\bar{X}_{B}\right)^{\prime} \hat{\beta}_{A}+$ $\bar{X}_{B}^{\prime}\left(\hat{\beta}_{A}-\hat{\beta}_{B}\right)(10)$

\section{Análise descritiva dos dados}

A base de dados utilizada neste artigo é o Censo de 2010, realizado pelo IBGE. Embora a maioria dos trabalhos encontrados na literatura utilize a base de dados da PNAD, optou-se pelo uso do Censo porque possui uma amostra com um número muito superior de observações em relação à PNAD (aproximadamente 1.380 milhão de observações somente para o Rio Grande do Sul em 2010, enquanto que a PNAD, em 2009, por exemplo, possuía 399.387 observações relativas ao Brasil). Esta base de dados possibilita, por exemplo, a desagregação da variável de escolaridade por níveis de escolaridade, o que torna-se um diferencial em relação a outros trabalhos.

As variáveis selecionadas foram as seguintes: salário obtido por meio do trabalho principal, horas trabalhadas por semana, gênero do indivíduo, raça (cor) do indivíduo, indivíduos que estão em idade para ocupar vaga no mercado de trabalho (População em Idade Ativa - PIA), indivíduos que residem na zona urbana, indivíduos que ocupam posição de referência no domicílio, anos de escolaridade, se o indivíduo recebe aposentadoria, alguma bolsa de auxílio (bolsa família, por exemplo) ou outra fonte de renda que não seja o salário obtido por meio do trabalho principal e se o indivíduo trabalha em um emprego formal ou informal. A Tabela 1 apresenta as estatísticas descritivas dessas variáveis. 
Tabela 1. Estatísticas Descritivas

\begin{tabular}{|c|c|c|c|}
\hline Variáveis & Definição & Homens & Mulheres \\
\hline Salário hora & Logaritmo do salário por hora & $\begin{array}{c}8,1684 \\
(17,9668)\end{array}$ & $\begin{array}{c}6,9626 \\
(14,5867)\end{array}$ \\
\hline Trabalha & Sim/Não (Referência: Sim) & $\begin{array}{c}0,9641 \\
(0,1860)\end{array}$ & $\begin{array}{c}0,9383 \\
(0,2407)\end{array}$ \\
\hline Raça & $1=$ Amarela; $0=$ Outras & $\begin{array}{c}0,0031 \\
(0,0559)\end{array}$ & $\begin{array}{c}0,0035 \\
(0,0676)\end{array}$ \\
\hline Experiência (média) & $\begin{array}{l}\text { Idade menos o tempo de serviço } \\
\text { do indivíduo menos } 6\end{array}$ & $\begin{array}{c}22,8429 \\
(12,8878)\end{array}$ & $\begin{array}{l}22,3899 \\
(12,6498)\end{array}$ \\
\hline Zona urbana & $\begin{array}{c}\text { Urbana/Rural (Referência: } \\
\text { Urbana) }\end{array}$ & $\begin{array}{c}0,8281 \\
(0,3773)\end{array}$ & $\begin{array}{c}0,8494 \\
(0,3577)\end{array}$ \\
\hline Aposentadoria & $\begin{array}{c}\text { Recebe/Não recebe (Referência: } \\
\text { Recebe) }\end{array}$ & $\begin{array}{c}0,0476 \\
(0,2130)\end{array}$ & $\begin{array}{c}0,0749 \\
(0,2632)\end{array}$ \\
\hline Bolsa Auxílio & $\begin{array}{l}\text { Recebe/Não recebe (Referência: } \\
\text { Recebe) }\end{array}$ & $\begin{array}{c}0,0070 \\
(0,0836)\end{array}$ & $\begin{array}{c}0,0595 \\
(0,2365)\end{array}$ \\
\hline Outras rendas & $\begin{array}{l}\text { Recebe/Não recebe (Referência: } \\
\text { Recebe) }\end{array}$ & $\begin{array}{c}0,0491 \\
(0,2160)\end{array}$ & $\begin{array}{c}0,0492 \\
(0,2163)\end{array}$ \\
\hline Responsável pelo domicílio & Sim/Não (Referência: Sim) & $\begin{array}{c}0,5368 \\
(0,4986)\end{array}$ & $\begin{array}{c}0,3058 \\
(0,4607)\end{array}$ \\
\hline Tipo de emprego & $\begin{array}{l}\text { Formal/Informal (Referência: } \\
\text { Formal) }\end{array}$ & $\begin{array}{c}0,5855 \\
(0,4926)\end{array}$ & $\begin{array}{c}0,6156 \\
(0,4865)\end{array}$ \\
\hline Escolaridade (média) & Anos de estudo & $\begin{array}{r}8,8706 \\
(3,7104) \\
\end{array}$ & $\begin{array}{c}9,7022 \\
(3,9634)\end{array}$ \\
\hline \multicolumn{2}{|c|}{ Distribuição por nível de escolaridade } & Homens & Mulheres \\
\hline Creche & & $0,22 \%$ & $0,15 \%$ \\
\hline EJA & & $0,32 \%$ & $0,28 \%$ \\
\hline Primário & & $4,22 \%$ & $3,92 \%$ \\
\hline Ginásio & & $1,12 \%$ & $1,03 \%$ \\
\hline Fundamental $1^{\mathrm{a}}-3^{\mathrm{a}}$ série & & $9,09 \%$ & $7,10 \%$ \\
\hline Fundamental $4^{a}-5^{a}$ série & & $10,74 \%$ & $9,15 \%$ \\
\hline Fundamental $6^{a}-8^{a}$ série & & $25,99 \%$ & $20,81 \%$ \\
\hline Supletivo & & $3,50 \%$ & $2,93 \%$ \\
\hline Científico & & $0,61 \%$ & $0,72 \%$ \\
\hline Ensino Médio & & $31,57 \%$ & $33,50 \%$ \\
\hline Superior & & $10,48 \%$ & $15,72 \%$ \\
\hline Especialização & & $1,51 \%$ & $3,73 \%$ \\
\hline Mestrado & & $0,43 \%$ & $0,71 \%$ \\
\hline Doutorado & & $0,20 \%$ & $0,25 \%$ \\
\hline
\end{tabular}

Fonte: Elaboração própria a partir de dados do Censo 2010 - IBGE. 
A variável "salário médio por hora" ${ }^{3}$ é elaborada a partir da divisão do salário obtido por meio do trabalho principal por 4,2 (com base em um mês de 30 dias divididos pelos sete dias da semana) e depois pela variável que representa as horas trabalhadas por semana. A variável referente ao gênero do indivíduo é uma variável binária, na qual assume valor 1 se o indivíduo é do sexo masculino e 0 caso seja do sexo feminino. De acordo com a Tabela 1, ao se analisar o salário médio (hora) por gênero ${ }^{4}$, constata-se que os homens possuem salários, em média, aproximadamente $15 \%$ maiores do que o das mulheres no Rio Grande do Sul.

A variável que representa nível de escolaridade é definida pelos anos de estudo completos. Como se pode observar, as mulheres possuem, em média, quase um ano de estudo a mais que os homens. A base de dados do Censo permite uma análise diferenciada dos graus de qualificação concluídos em relação à base de dados da PNAD, uma vez que torna possível verificar o impacto, a partir da estimação da equação minceriana, de cada nível concluído nos salários dos indivíduos. Isso poderá ser observado na próxima seção. Por hora, é relevante destacar o maior percentual de participação das mulheres gaúchas nos níveis mais elevados de qualificação em relação aos homens. No nível de mestrado, por exemplo, o percentual de mulheres que concluem este grau é quase $40 \%$ maior que o percentual de homens que concluem essa etapa.

A variável experiência é definida pela expressão proposta por Mincer (1974) como sendo igual à idade em anos completos, subtraída pelos anos de estudos completos menos seis, pois presume-se que o indivíduo começa a frequentar a escola a partir dos seis anos de idade. Em se tratando do nível médio de experiência, nota-se que as mulheres possuem apenas $2 \%$ a menos que os homens. Cabe ressaltar que a variável experiência será incluída na estimação da equação de salários na forma quadrática, com o objetivo de captar possíveis não linearidades na relação entre rendimentos e experiência.

A variável zona urbana é uma variável dummy, na qual possui valor 1 se 0 indivíduo reside na zona urbana e 0, caso contrário. Segundo Queiroz e Moreira (2008), essa dummy para local de residência mostra que as pessoas que se encontram no meio urbano possuem maiores oportunidades de engajamento no mercado de trabalho.

A variável dummy para responsável pelo domicílio assume valor 1 se 0 indivíduo é a pessoa de referência em tal domicílio e 0 , caso contrário. Como se pode observar na Tabela 1, mais de 50\% dos homens são responsáveis pelos seus domicílios e apenas 31\% das mulheres possuem este status. Essa constatação está em consonância com a ideia de Psacharopoulos e Tzannatos (1992), quando afirmam que as mulheres possuem oferta elástica no mercado de trabalho e os homens, oferta inelástica, pois estes se veem obrigados a trabalhar para sustentarem os domicílios pelos quais são responsáveis.

De acordo com Queiroz e Moreira (2008), a variável raça é utilizada para verificar qual categoria tem mais oportunidades de entrar no mercado de trabalho, comparando com os indivíduos que consideram brancos e não brancos. Para o Rio

\footnotetext{
${ }^{3}$ Conforme é recomendado pela metodologia proposta por Mincer (1974).

${ }^{4}$ Neste trabalho será avaliado o gênero, pois este se refere às relações sociais desiguais de poder entre homens e mulheres que são resultado de uma construção social do papel do homem e da mulher a partir das diferenças sexuais (biológicas).
} 
Grande do Sul, será utilizada a cor amarela como referência, para que seja possível corrigir ao máximo os erros de autoavaliação, ou seja, como os indivíduos de cor amarela estão em menor percentual $(0,36 \%)$, pretende-se amenizar o problema de autodenominação, visto que muitos indivíduos que se consideram brancos, podem ser amarelos. Além disso, parte-se do pressuposto de que aqueles que se consideram amarelos são, de fato, amarelos.

As variáveis que representam outras fontes de renda que não sejam oriundas do trabalho principal (aposentadoria, bolsas de auxílio e outras fontes) são dummies que possuem valor 1 se o indivíduo possuir uma destas fontes de renda e 0 , caso contrário. Conforme a Tabela 1 , as mulheres recebem maiores percentuais de outras fontes de renda em relação aos homens. Isso pode ser explicado pelo fato das mulheres estarem aptas a receberem pensões por toda sua vida, enquanto que os homens só as recebem até uma determinada idade. Ademais, é importante destacar que essas variáveis serão utilizadas nas estimações porque elas reduzem a probabilidade de o indivíduo estar trabalhando, ou seja, os indivíduos exigiriam altos salários de reserva para trocarem seu lazer por trabalho.

Também tem-se a variável que avalia se o indivíduo está inserido no mercado de trabalho ou não. Se o indivíduo em questão possuir renda maior que zero e estiver no intervalo de idade ${ }^{5}$ que compreende a PIA, ele será considerado inserido no mercado de trabalho, e, caso contrário, não inserido. Como se observa, os homens em idade ativa estão inseridos no mercado de trabalho em maiores percentuais que as mulheres. Isso sugere a existência de um viés de seleção, visto que há um percentual fora do mercado de trabalho em ambos os sexos $(3,6 \%$ homens e 6,2\% mulheres). Entretanto, esse maior percentual de mulheres fora do mercado pode ser justificado pelo fato de estas, em geral, estarem ocupadas com outras obrigações (filhos, família), o que tende a diminuir sua permanência em atividades fora de seu domicílio.

Com relação ao tipo de emprego ${ }^{6}$, verifica-se que os empregos formais representam a maior parte dos postos de trabalho no Rio Grande do Sul, uma vez que aproximadamente $60 \%$ dos indivíduos locais estão alocados nestes postos. As mulheres ocupam $4,8 \%$ a mais de empregos formais que os homens. De acordo com Cacciamali e Fernandes (2003), Fernandes (1996), Tannuri-Pianto e Pianto (2002), os trabalhadores de atividades formais possuem maior nível de escolaridade média que os trabalhadores informais, sugerindo a existência de segmentação no mercado de trabalho, ou seja, trabalhadores com baixa escolaridade tendem a inserirem-se em empregos informais por não cumprirem as exigências para ingressarem em atividades formais. Conforme o observado, as mulheres possuem maior escolaridade média que os homens no estado, por isso, possivelmente, ocupem um percentual maior de empregos formais que os homens.

A Tabela 2 apresenta as características do mercado de trabalho do Rio Grande do Sul. Para esta análise, utilizou-se como referência a Classificação Nacional de Atividades Econômicas - CNAE, a qual está contida na base de dados do Censo 2010. Além disso, a divisão das categorias foi elaborada de acordo com a realizada por Giuberti e Menezes-Filho (2005), possuindo apenas algumas

\footnotetext{
${ }^{5}$ De 16 a 65 anos de idade.

${ }^{6}$ Esta variável assume valor 1 quando o indivíduo está trabalhando com carteira assinada (Emprego Formal) e 0 quando ele está trabalhando sem carteira assinada (Emprego Informal).
} 
alterações com relação à citada organização. Exemplo disso é a inclusão dos serviços domésticos na análise. Essa variável é importante para a estimação dos modelos econométricos a serem realizados, pois controla as heterogeneidades de características dos setores da economia na equação de salários.

Primeiramente, ressalta-se o setor agrícola, que compreende atividades como agricultura, pecuária, produção florestal, pesca e aquicultura, sendo a atividade econômica responsável por quase um quarto da ocupação dos indivíduos do Rio Grande do Sul. Dessa forma, esse setor ainda se destaca como o de maior potencial econômico do estado, sendo acompanhado pela Indústria da Transformação e pelo Comércio.

Tabela 2. Características do mercado de trabalho no Rio Grande do Sul

\begin{tabular}{|c|c|c|c|c|}
\hline \multirow{2}{*}{ Setores } & \multirow{2}{*}{$\begin{array}{l}\text { Frequência } \\
\text { percentual }\end{array}$} & \multicolumn{2}{|c|}{ Participação \% } & \multirow{2}{*}{$\begin{array}{l}\text { Rendimento médio } \\
\text { (hora) por setor }\end{array}$} \\
\hline & & Homens & Mulheres & \\
\hline Agrícola & $24,59 \%$ & $62 \%$ & $38 \%$ & 4,18 \\
\hline Indústria da Transformação & $15,22 \%$ & $61 \%$ & $39 \%$ & 6,25 \\
\hline Outras atividades industriais & $3,10 \%$ & $94 \%$ & $6 \%$ & 6,70 \\
\hline Indústria da Construção & $6,17 \%$ & $97 \%$ & $3 \%$ & 5,92 \\
\hline Comércio de mercadorias & $14,77 \%$ & $56 \%$ & $44 \%$ & 6,41 \\
\hline Prestação de serviços & $2,02 \%$ & $37 \%$ & $63 \%$ & 6,69 \\
\hline Transporte e comunicação & $4,62 \%$ & $86 \%$ & $14 \%$ & 8,34 \\
\hline Administração Pública & $5,09 \%$ & $60 \%$ & $40 \%$ & 11,08 \\
\hline Educação & $4,61 \%$ & $19 \%$ & $81 \%$ & 10,61 \\
\hline Social & $3,00 \%$ & $20 \%$ & $80 \%$ & 10,62 \\
\hline Serviços domésticos & $5,70 \%$ & $7 \%$ & $93 \%$ & 4,01 \\
\hline Outras atividades & $13,90 \%$ & $52 \%$ & $48 \%$ & 8,38 \\
\hline
\end{tabular}

Fonte: Elaboração própria a partir de dados do Censo 2010 - IBGE.

Como se observa, as mulheres dominam a participação em atividades como Educação, Serviços Sociais, Serviços domésticos, sendo os dois primeiros citados pertencentes ao grupo dos três setores com os maiores salários médios (hora) registrados (10,61 e 10,62 reais, respectivamente), e o último o que menos remunera em relação aos setores analisados (4,01 reais). Entretanto, esses setores apresentam baixo percentual de participação, ou seja, representam apenas $13,31 \%$ da ocupação dos trabalhadores do estado. Já os homens ocupam-se, em maior quantidade com relação às mulheres, em setores como Indústria da Construção, Indústria Extrativa e nos Transportes e Comunicação. Também, estão alocados em maior percentual na Administração Pública, setor este que possui o maior salário médio (hora) em comparação com os outros setores avaliados $(11,08$ reais).

Um importante ponto a se destacar com relação aos salários médios (hora) é que os homens estão inseridos nas faixas de renda mais elevadas, enquanto que as mulheres estão inseridas nas faixas inferiores, conforme mostra a Tabela 3. Além disso, destaca-se a relação inversa de participação entre homens e mulheres, 
ou seja, as mulheres vão diminuindo sua participação à medida que o nível de renda aumenta. Contrariamente, os homens participam em proporção menor nas faixas de salário inferiores, aumentando sua participação nos níveis mais elevados.

Tabela 3. Percentual de rendimentos por nível de homens e mulheres no Rio Grande do Sul

\begin{tabular}{ccc}
\hline Quintis de renda & Homens & Mulheres \\
\hline 1 & $47,9 \%$ & $52,1 \%$ \\
2 & $47,9 \%$ & $52,1 \%$ \\
3 & $54,2 \%$ & $45,8 \%$ \\
4 & $62,2 \%$ & $37,8 \%$ \\
5 & $60,3 \%$ & $39,7 \%$ \\
\hline
\end{tabular}

Fonte: Elaboração própria a partir de dados do Censo 2010 - IBGE.

Como se pôde ver na Tabela 2, as mulheres ocupam-se, em sua maioria,em postos de trabalho que remuneram com valores mais baixos que os postos ocupados majoritariamente pelos homens. Esse fato pode ser uma possível justificativa para esse cenário inverso da distribuição dos níveis de renda entre os gêneros.

Portanto, após esta análise das variáveis, a próxima seção traz a estimação da equação de salários, assim como a decomposição do diferencial destes salários entre os gêneros no estado do Rio Grande do Sul.

\section{Resultados}

Para a realização da estimação da equação de salários do trabalho do tipo mincerianas para o Rio Grande do Sul, de acordo com o modelo proposto por Heckman (1979), deve-se, primeiramente, estimar uma equação de seleção, ou seja, uma equação que avalie a decisão do indivíduo em estar inserido no mercado de trabalho ou não. Para isso, as variáveis "aposentadoria", "bolsas de auxílio", "outras fontes de renda" foram incluídas no modelo como fatores que afetam negativamente na escolha do indivíduo em ofertar trabalho. Já a variável "responsável pelo domicílio" representa um aspecto positivo em relação a esta decisão. Estas são as variáveis de exclusão do procedimento de Heckman (1979), ou seja, são variáveis que afetam a probabilidade de um indivíduo ofertar ou não trabalho, mas não afetam diretamente os salários do mesmo. A Tabela 4 mostra os resultados dessa primeira etapa. 
Tabela 4. Estimação da equação de seleção - Efeitos marginais - Rio Grande do Sul

\begin{tabular}{lcc}
\hline \multicolumn{1}{c}{ Variáveis } & \multicolumn{2}{c}{$\begin{array}{c}\text { Probit. Decisão de ofertar trabalho } \\
{[1=\text { oferta trabalho; } 0=\text { não oferta] }} \\
\text { Coeficientes }\end{array}$} \\
\hline Sexo & $0,3532^{* * *}$ & 0,0029 \\
Raça & $-0,1597^{* * *}$ & 0,0193 \\
Anos de escolaridade & $0,0367^{* * *}$ & 0,0005 \\
Experiência & $0,2029^{* * *}$ & 0,0004 \\
Experiência ao quadrado & $-0,0005^{* * *}$ & 0,0000 \\
Zona urbana & $1,1093^{* * *}$ & 0,0027 \\
Aposentadoria & $-0,4497^{* * *}$ & 0,0043 \\
Bolsa de auxílio & $-0,3961^{* * *}$ & 0,0052 \\
Outras fontes de renda & $-0,1023^{* * *}$ & 0,0056 \\
Responsável pelo domićlio & $0,2425^{* * *}$ & 0,0030 \\
Constante & $0,4792^{* * *}$ & 0,0067 \\
\hline
\end{tabular}

Fonte: Elaboração própria a partir de dados do Censo 2010 - IBGE.

$*{ }^{*}$ Coeficientes significativos a $1 \%$.

De acordo com os coeficientes estimados, receber esses tipos de renda diminui a probabilidade de ofertar trabalho dos indivíduos que as recebem, visto que, por terem elevados salários de reserva, exigiriam salários maiores que estes para trocarem suas atividades de lazer por trabalho. Já os indivíduos que exercem - papel de chefe de família (responsabilidade pelo domicílio) possuem aproximadamente $24 \%$ a mais de probabilidade de ofertar trabalho em relação àqueles que não estão nesta posição. Além disso, conforme destacam Queiroz e Moreira (2008), se o chefe da família for homem, a probabilidade de ele estar inserido no mercado de trabalho é maior que a da mulher. Tal fato se confirma na análise para o Rio Grande do Sul, onde ser do sexo masculino aumenta esta probabilidade de inserção em mais 1,66\%.

O termo experiência ao quadrado apresentou sinal negativo, confirmando a hipótese de depreciação do capital humano. Assim, à medida que a idade avança, a probabilidade de participação no mercado de trabalho diminui (SALVATO; SILVA, 2008).

A variável referente ao gênero (sexo) possui um coeficiente elevado, ou seja, o fato do indivíduo ser do sexo masculino aumenta em 35\% a possibilidade de estar inserido no mercado de trabalho. Já com relação à raça, tal qual destacam Queiroz e Moreira (2008), o parâmetro negativo indica que os indivíduos não amarelos estão com maiores possibilidades de estarem inseridos neste mercado.

Os anos de escolaridade indicam que cada ano a mais de estudo aumenta a possibilidade do indivíduo estar trabalhando, resultado semelhante ao encontrado por Scorzafave e Menezes-Filho (2001). No que diz respeito ao local de residência, vê-se que os indivíduos que residem no meio urbano do Rio Grande do Sul possuem mais de $100 \%$ de chance de ofertar trabalho no mercado. Esse resultado confirma a suposição levantada na seção anterior, onde se afirmava que residir na 
zona urbana aumentaria as chances dos indivíduos receberem mais oportunidades no mercado de trabalho.

Após realizado o primeiro estágio do modelo de Heckman (equação de seleção), parte-se para a estimação da equação de rendimentos. A Tabela 5 apresenta os seus resultados.

Tabela 5. Estimação da equação de salários para o Rio Grande do Sul

\begin{tabular}{|c|c|c|c|c|}
\hline \multirow{3}{*}{ Variáveis } & \multicolumn{4}{|c|}{ Variável dependente: logaritmo do salário (hora) } \\
\hline & \multicolumn{2}{|c|}{ Heckman } & \multicolumn{2}{|c|}{ MQO } \\
\hline & Coeficientes & Erro Padrão & Coeficientes & Erro Padrão \\
\hline Experiência & 0,0319 & 0,0001 & 0,0320 & 0,0001 \\
\hline Experiência ao quadrado & $-0,0004$ & 0,0000 & $-0,0004$ & 0,0000 \\
\hline Raça & $-0,0347$ & 0,0060 & $-0,0353$ & 0,0060 \\
\hline Sexo & 0,2388 & 0,0009 & 0,2404 & 0,0008 \\
\hline Zona urbana & 0,1261 & 0,0020 & 0,1319 & 0,0013 \\
\hline Tipo de emprego (Formal ou Informal) & 0,0736 & 0,0008 & 0,0737 & 0,0008 \\
\hline Lambda & $-0,0270$ & 0,0069 & & \\
\hline Constante & 0,6888 & 0,0085 & 0,6794 & 0,0081 \\
\hline \multicolumn{5}{|l|}{ Níveis de escolaridade } \\
\hline Eja & 0,0548 & 0,0100 & 0,0547 & 0,0100 \\
\hline Primário & $-0,0921$ & 0,0081 & $-0,0920$ & 0,0081 \\
\hline Ginásio & 0,1291 & 0,0085 & 0,1304 & 0,0085 \\
\hline Fundamental $1^{\mathrm{a}}-3^{\mathrm{a}}$ & $-0,1606$ & 0,0080 & $-0,1604$ & 0,0080 \\
\hline Fundamental $4^{a}-5^{a}$ & $-0,0836$ & 0,0080 & $-0,0829$ & 0,0080 \\
\hline Fundamental $6^{a}-8^{a}$ & 0,0372 & 0,0079 & 0,0382 & 0,0079 \\
\hline Supletivo & 0,1303 & 0,0081 & 0,1313 & 0,0081 \\
\hline Científico & 0,4412 & 0,0089 & 0,4427 & 0,0089 \\
\hline Ensino Médio & 0,3115 & 0,0079 & 0,3127 & 0,0079 \\
\hline Superior & 0,9946 & 0,0080 & 0,9960 & 0,0080 \\
\hline Especialização & 1,3447 & 0,0082 & 1,3463 & 0,0082 \\
\hline Mestrado & 1,6340 & 0,0091 & 1,6354 & 0,0091 \\
\hline Doutorado & 2,0637 & 0,0107 & 2,0651 & 0,0106 \\
\hline \multicolumn{5}{|l|}{ Setores da economia } \\
\hline Agrícola & $-0,2243$ & 0,0016 & $-0,2246$ & 0,0016 \\
\hline Indústria da Transformação & 0,0188 & 0,0063 & 0,0191 & 0,0063 \\
\hline Outras atividades industriais & $-0,0293$ & 0,0012 & $-0,0294$ & 0,0012 \\
\hline Indústria da Construção & $-0,0618$ & 0,0015 & $-0,0618$ & 0,0015 \\
\hline Comércio de mercadorias & $-0,0641$ & 0,0012 & $-0,0641$ & 0,0012 \\
\hline Prestação de serviços & 0,2080 & 0,0017 & 0,2079 & 0,0017 \\
\hline Transporte e comunicação & $-0,0557$ & 0,0018 & $-0,0555$ & 0,0018 \\
\hline Administração Pública & 0,1241 & 0,0019 & 0,1243 & 0,0019 \\
\hline Educação & 0,0020 & 0,0023 & 0,0022 & 0,0023 \\
\hline Social & $-0,2090$ & 0,0016 & $-0,2089$ & 0,0016 \\
\hline Serviços domésticos & 0,0546 & 0,0016 & 0,0544 & 0,0016 \\
\hline
\end{tabular}

Fonte: Elaboração própria a partir de dados do Censo 2010 - IBGE. Nota: Todos os coeficientes significativos a $1 \%$. 
Importante destacar que o Modelo de Heckman mostrou resultados mais robustos que os obtidos pela estimação por $\mathrm{MQO}$, uma vez que o coeficiente da variável Lâmbda foi estatisticamente significativo. Assim, sua inserção tornou-se imprescindível para a correção da seletividade amostral (RESENDE; WYLLIE, 2008) e, por consequência, do viés dos coeficientes estimados.

O sinal negativo do coeficiente da variável Lâmbda é igual ao encontrado por Kassouf (1994) e Resende e Wyllie (2006). Segundo eles, esse sinal indica que fatores não mensurados que aumentam a probabilidade de participação no mercado de trabalho diminuem os salários. Psacharopoulos e Tzannatos (1992) explicam que o sinal negativo do coeficiente desta variável se deve ao fato de que, para as mulheres, por exemplo, as recompensas para atividades domiciliares são mais elevadas que as obtidas no mercado de trabalho. Dessa forma, variáveis não observáveis que aumentam a produtividade em casa podem relacionar positivamente os retornos a esse mercado.

Embora o elevado diferencial estimado dê indícios de que existe discriminação no mercado de trabalho em favor dos homens $(23,9 \%)$, ele não pode representar a real magnitude. Para isso, é necessário realizar o controle das características dos indivíduos para que se confirme essa hipótese, conforme será apresentado na Decomposição de Oaxaca-Blinder.

A variável experiência apresentou resultados consoantes com a literatura, mostrando um crescimento a taxas decrescentes, caracterizando o formato de " $U$ " invertido, conforme destacam Cavalieri e Fernandes (1998). Segundo os autores, essa variável captura o decréscimo de produtividade que provavelmente ocorre quando o indivíduo atinge determinada idade. O efeito marginal máximo é em 40,1 anos de idade, ou seja, neste ponto os trabalhadores do Rio Grande do Sul, em média, atingem o auge de suas produtividades. A partir desse momento, essas taxas começam a diminuir, assumindo-se a existência de uma relação direta entre salários e produtividade.

O coeficiente negativo da variável raça (cor) mostrou não existir efeito discriminatório para este caso no Rio Grande do Sul, pois ser da cor amarela não implica em diferentes retornos nos rendimentos. Dessa forma, esse resultado indica que as outras raças possuem espaço nesse mercado de trabalho.

Com relação aos retornos dos níveis de escolaridade, é importante ressaltar o seu importante papel nos salários. Como se observa, quanto maiores os níveis de escolaridade concluídos, maiores são os retornos nos salários. Por exemplo, a conclusão do ensino médio gera um retorno de 31,15\% nos salários dos gaúchos, assim como a conclusão dos níveis científico, aumenta em $48,2 \%$ tais retornos. A conclusão do nível superior impulsiona, em média, em $106 \%$ os salários dos indivíduos do Rio Grande do Sul. Nos níveis de pós-graduação, as recompensas salariais são ainda maiores: a especialização gera um retorno de 143\%, o mestrado impulsiona em $171 \%$ os salários e o doutorado, $212 \%$. Essas comparações são feitas com o nível mais baixo de educação, que neste caso é o nível pré-escolar (presume-se que nesse nível o indivíduo esteja começando a agregar o capital humano que será necessário para o desenvolvimento de sua produtividade no trabalho). Tais resultados permitem concluir que a educação é valorizada no mercado de trabalho (BARBOSA FILHO; PESSÔA, 2008). 
Usando como base o ensino médio, concluir o nível científico ${ }^{7}$ acarreta em um prêmio salarial de 12,97\%. Cabe frisar que, mesmo que os níveis médio e científico representem o mesmo número de anos de estudo, os retornos são distintos, o que pode refletir em uma queda na qualidade de ensino da educação básica (ensino médio) no Rio Grande do Sul.

Também, o prêmio pela conclusão do ensino superior é de $68,31 \%$, em comparação com o ensino médio, ou seja, uma mudança acentuada nos retornos a partir da conclusão deste nível mais elevado. Um argumento para essa mudança pode estar relacionado ao fato de que o ensino médio, nos moldes atuais, não qualifica para nenhuma profissão, ao contrário do que ocorre com a obtenção do título de nível superior, que habilita o indivíduo a uma profissão específica. Comparando-se com Barros e Ramos (1994), esses retornos no Brasil, com o mesmo número de anos de estudo, nos anos 1970 e 1980, não passavam de $22 \%$. Porém, cabe ressaltar que essa diferença elevada pode estar associada a diferenças no método de estimação, visto que Barros e Ramos (1994) estimaram os retornos da escolaridade por MQO, diferentemente do realizado neste artigo.

Barbosa Filho e Pessôa (2008) e Siqueira e Suliano (2009) destacam o "efeito diploma" que é refletido em prêmios salariais mais elevados à medida que são completos ciclos de educação, ressaltando a importância do término de pelo menos um ciclo de estudo. Essa característica reforça a importância de se concluir uma graduação, pois, conforme mostram os resultados, isso pode gerar uma alavancagem nos salários e, por conseguinte, um aumento no padrão de vida dos indivíduos. Também, destaca-se o efeito diploma para a conclusão de pósgraduação, visto que a conclusão do mestrado gera um prêmio salarial de 63,94\% e, do doutorado, de 42,97\%, evidenciando que o mercado de trabalho do Rio Grande Sul valoriza o capital humano dos trabalhadores.

O controle para tipo de emprego mostrou que no Rio Grande do Sul os empregos formais remuneram melhor seus trabalhadores que o setor informal. Isto corrobora com o que se previu na análise descritiva dessa variável, onde constatou-se que nesse estado os empregos com carteira assinada são maioria e pagam maiores salários que os empregos sem carteira assinada.

A decomposição do diferencial de salários por gênero no Rio Grande do Sul é apresentada na Tabela 6 . Como se observa, os homens ganham, em média, $\mathrm{R} \$$ 1,15 real por hora a mais que as mulheres, o que significa um valor em termos mensais (em média) de $\mathrm{R} \$ 212,52$ em favor dos homens.

\footnotetext{
"Entende-se por "Ensino Médio" a etapa do sistema de ensino equivalente à última fase da educação básica, cuja finalidade é o aprofundamento dos conhecimentos adquiridos no ensino fundamental, bem como a formação do cidadão para a vida social e para o mercado de trabalho, oferecendo o conhecimento básico necessário para o estudante ingressar no ensino superior. Já o "Nível Científico ou Técnico" é um nível ou subsistema de ensino enquadrado no nível médio dos sistemas educativos, que constitui uma modalidade de ensino vocacional, orientada para a rápida integração do aluno no mercado de trabalho. Normalmente, corresponde a uma formação ao nível do ensino secundário.
} 
Tabela 6. Hiato salarial, Componente Explicado e Componente Não Explicado estimados para o estado do Rio Grande do Sul

\begin{tabular}{lcc}
\hline Logaritmo do salário (hora) & Coeficientes & Desvio Padrão \\
\hline Diferencial & & \\
Homens & 1,6154 & 0,0015 \\
Mulheres & 1,4706 & 0,0017 \\
\hline Hiato salarial estimado & 0,1448 & 0,0022 \\
\hline Decomposição & & \\
Componente Explicado & $-0,0534$ & 0,0014 \\
Componente Não Explicado & 0,1982 & 0,0022 \\
\hline
\end{tabular}

Fonte: Elaboração própria a partir de dados do Censo 2010 - IBGE.

*Todos os coeficientes significativos a $1 \%$.

O componente explicado apresentou um sinal negativo, o que permite concluir que os atributos produtivos não foram os responsáveis por este diferencial de salários. Essa afirmação pode estar alicerçada no fato de que as mulheres, embora possuam um pouco menos de experiência no mercado de trabalho em relação aos homens, possuem um nível de escolaridade $9 \%$ maior que eles.

No entanto, conforme destacam Giuberti e Menezes-Filho (2005), os valores de maior expressão para explicar o diferencial de salários por gênero encontram-se nos coeficientes do componente não explicado. Assim, o sinal positivo do coeficiente desse componente remete à existência de discriminação no mercado de trabalho do Estado do Rio Grande do Sul, ao tornar evidente que os atributos não observados dos indivíduos são mais valorizados que seus atributos produtivos (educação e experiência). Ou seja, o componente explicado, o qual é determinado pelos atributos produtivos, sendo negativo, implica que esses atributos são de maior magnitude nas mulheres. Mas, como o componente não explicado, que contém as características não observadas, apresenta-se positivo e elevado, além de possuir maior peso na formação do hiato salarial, são mais valorizados nos homens. Dessa forma, constata-se que os homens recebem, em média, $13,47 \%$ a mais que as mulheres no mercado de trabalho do estado, sendo esta diferença determinada pelas características pessoais (não produtivas) dos indivíduos. No Brasil, segundo Scorzafave e Pazello (2007), esse diferencial tem se mostrado menor, seguindo uma tendência de queda. De acordo com os autores, o diferencial de salários no Brasil diminui de 47\% em 1988 para 22\% em 2004, ou seja, 25\% a menos em 16 anos.

A Tabela 7 abaixo apresenta a decomposição detalhada dos componentes explicado e não explicado. Esta análise foi realizada de duas formas: primeiro, sem a utilização do controle para setores de atividade da economia e depois controlando esta variável. O objetivo dessa estratégia é verificar se a discriminação no mercado de trabalho do Rio Grande do Sul é intersetorial ou intrasetorial, isto é, identificar se a magnitude da discriminação é maior entre os setores da economia (alocativa) ou dentro de cada setor. Essa análise torna-se relevante pois pode existir segmentação em tal mercado: indivíduos com a mesma qualificação não 
possuírem o mesmo acesso a determinadas ocupações (BATISTA; CACCIAMALI, 2009).

Os resultados mostram que há um aumento do componente não explicado quando inclui-se o controle para as atividades econômicas, sugerindo que a discriminação intrasetorial tem um peso maior na discriminação em relação à constatada entre os setores da economia. Com este controle, a magnitude do componente discriminatório aumentou de $13,47 \%$ para $14,64 \%$, uma diferença positiva de $8,06 \%$. Esse resultado refuta a hipótese de segmentação no mercado de trabalho do Rio Grande do Sul, mas sinaliza que profissionais com qualificação e experiência semelhante (em um mesmo setor de atividade) recebem salários diferenciados nesse mercado por causa do seu gênero.

Observando-se o componente explicado, se apenas a experiência determinasse os salários, os homens ganhariam $R \$ 1,01$ a mais que as mulheres por hora trabalhada sem o controle para os setores e $R \$ 1,02$ a mais com 0 controle. Por outro lado, avaliando-se apenas pelos anos de escolaridade, as mulheres ganhariam $R \$ 1,10$ a mais por hora trabalhada que os homens, com e sem a inclusão do controle para os setores.

Tabela 7. Decomposição detalhada de Oaxaca-Blinder para as médias sem controle e com controle para atividades econômicas

\begin{tabular}{lcc}
\hline \multicolumn{1}{c}{ Componente Explicado } & Sem controle & Com controle \\
\hline Experiência & 0,0158 & 0,0162 \\
Experiência ao quadrado & $-0,0035$ & $-0,0042$ \\
Raça & 0,0000 & 0,0000 \\
Anos de escolaridade & $-0,0988$ & $-0,0985$ \\
Lambda & 0,0331 & 0,0273 \\
Setores da economia & & $-0,0112$ \\
\hline Total $\quad$ Componente Não Explicado & $-0,0534$ & $-0,0705$ \\
\hline & Sem controle & Com controle \\
\hline Experiência & 0,2521 & 0,2574 \\
Experiência ao quadrado & $-0,1217$ & $-0,1270$ \\
Raça & $-0,0001$ & $-0,0002$ \\
Anos de escolaridade & $-0,0099$ & $-0,0324$ \\
Lambda & $-0,0528$ & 0,0412 \\
Setores da economia & & 0,0431 \\
\hline Total & 0,1982 & 0,2153 \\
\hline
\end{tabular}

Fonte: Elaboração própria a partir de dados do Censo 2010 - IBGE.

*Todos os parâmetros foram significativos a $1 \%$.

Analisando-se o componente não explicado, verifica-se que mulheres com o mesmo nível de experiência dos homens ganham, em média, $\mathrm{R} \$ 1,29$ a menos por hora trabalhada do que eles, sem alterações significativas quando se analisa com e sem o controle para os setores da economia. Com relação aos anos de 
escolaridade, mulheres com o mesmo número de anos de escolaridade ganham aproximadamente $\mathrm{R} \$ 1,01$ a menos que os homens por hora trabalhada sem 0 controle para os setores da economia, e R\$1,03 a menos quando inclui-se este controle. Em termos mensais, isso equivale a uma diferença salarial de aproximadamente $\mathrm{R} \$ 186,65$, em média. Ou seja, embora as mulheres no Rio Grande do Sul possuam mais anos de escolaridade que os homens, em média, esse atributo é mais valorizado em favor dos homens. Queiroz e Moreira (2008) ratificam essa constatação, pois segundo eles, nesses casos, o componente residual (não explicado) é tão grande que anula as vantagens e reverte o hiato em benefício dos homens, apesar da mulher possuir melhores atributos produtivos.

\section{Conclusões}

Este artigo representa uma contribuição à literatura que estuda os diferenciais de salários por gênero no Rio Grande do Sul por analisar como tais diferenciais são explicados neste estado. Ao se estimar a equação de salários, ficou comprovada a necessidade de correção para o problema de seletividade amostral. Ainda, a partir desse método, tornou-se possível identificar os retornos para escolaridade nos salários.

O presente trabalho apresentou um procedimento diferenciado no que diz respeito à identificação dos retornos dos vários níveis de escolaridade, a partir de sua desagregação por nível de qualificação. Desse modo, ficou aparente a contribuição não linear da educação nos salários, evidenciando o fato de que quanto maiores níveis de educação forem alcançados, maiores serão os retornos obtidos. Como foi observado, o prêmio pela conclusão do ensino superior, por exemplo, é de 68,31\%, comparando-se com os retornos obtidos por meio do ensino médio.

Ainda, é importante que se ressalte a colaboração deste estudo para reflexões importantes relativas à educação no Rio Grande do Sul. Por meio da abordagem realizada, constatou-se que o investimento em educação é altamente atrativo, dado as elevadas taxas de retorno que disponibiliza aos seus trabalhadores. Entretanto, é essencial que se repense a questão da educação básica no estado, visto que os retornos originados pela qualificação no ensino médio, principalmente, são muito pequenos, levando a crer que essa formação pouco está alterando a produtividade dos indivíduos do Rio Grande do Sul. Ademais, mesmo representando os mesmos anos de estudo e possuindo o mesmo objetivo quanto à formação profissional, o nível científico apresentou maiores retornos que o ensino médio (12,97\% a mais), tornando evidente a diferença de qualidade entre estas duas formações.

A partir da decomposição do diferencial de salários por meio do procedimento proposto por Oaxaca (1973) e Blinder (1973), constatou-se a existência de discriminação estatística contra as mulheres no mercado de trabalho do estado. Embora as mulheres possuam, em média, um ano a mais de escolaridade que os homens, tal magnitude não está sendo revertida nos seus salários. Os resultados apresentados mostraram que, se a escolaridade das mulheres fosse valorizada, elas receberiam maiores salários que os homens.

É importante destacar que os resultados mostraram que, no Rio Grande do Sul, a discriminação intrasetorial tem maior peso no diferencial de salários que a 
discriminação intersetorial (alocativa). Tal resultado contraria trabalhos como o de Batista e Cacciamnali (2009), os quais sugerem que parte desse elemento não explicado está relacionado à segmentação de mercado. Entretanto, esse resultado reflete uma média e ignora prováveis heterogeneidades dos mercados de trabalho das diferentes regiões do estado. Um estudo que avalie estes aspectos para estas regiões seria o ideal para dar mais consistência à afirmação (ou refutá-la) de que a discriminação salarial por gênero no Rio Grande do Sul tem maior peso intrasetorialmente do que intersetorialmente.

Outrossim, mesmo que com menor magnitude, verificou-se que esse diferencial de salários pode estar relacionado a questões alocativas, ou seja, os empregadores podem estar segregando por gênero na hora de contratar seus funcionários, gerando reflexos negativos na média dos salários obtidos pelas mulheres. Esse fato torna-se evidente ao constatar-se que existe discriminação intersetorial no mercado de trabalho gaúcho. Conforme ressalta Goldin (2002), regras sindicais e políticas de empresas têm sido usadas para restringir a entrada de mulheres em postos de trabalho que exijam, por exemplo, força "braçal" em vez de "cérebro".

Por outro lado, não se exclui a possibilidade de um problema de autoseleção, isto é, as próprias mulheres eximirem-se de determinados tipos de trabalhos. De acordo com O'Neill e O'Neill (2005), as diferenças salariais entre os gêneros reside na ideia da "não comodidade", pois, segundo o autor, homens e mulheres diferem de atitudes. Como verificou-se neste trabalho, o percentual de homens responsáveis pelo seu domicílio é $42,59 \%$ maior que o percentual de mulheres nesta condição. Logo, os homens possuem maior responsabilidade de fornecer recursos financeiros à família e, consequentemente, trabalham mais, mais continuamente, além de se submeterem, em maior probabilidade que as mulheres, a empregos de difícil execução.

Entretanto, a base de dados do Censo não permite que se controle esses aspectos subjetivos nas estimações. De fato, essa é uma lacuna existente neste trabalho, mas que levanta uma questão relevante a respeito dos meios de inserção da mulher no mercado de trabalho, podendo ser preenchida com novos estudos.

\section{REFERÊNCIAS}

ACEMOGLU, D.; AUTOR, D.. Lectures in Labor Economics. Massachusetts Institute of Technology - MIT Economics. Disponível em:

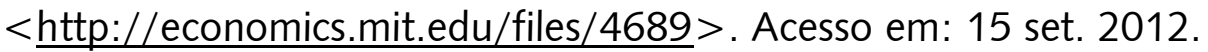

ARROW, J. K..The Economic Implications of Learning by Doing. The Review of Economic Studies, vol. 29, n. 3, p. 155-173, jun., 1962.

BARBOSA FILHO, F. H.; PESSOA, S. A.. O Retorno da Educação no Brasil. Pesquisa e Planejamento Econômico. Rio de Janeiro, v. 38, p. 97-125, 2008.

BARROS, R. P.; RAMOS, L.. A note on the temporal evolution of the relationship between wages and education among Brazilian prime-age males: 1976 - 1989. In: MENDONÇA, R.; URANI, A. (orgs). Estudos Sociais e do Trabalho. Rio de Janeiro: IPEA, 1994. 
BARROS, R. P. de; RAMOS, L.; SANTOS, E. Gender Differences in Brazilian Labor Market, In: SCHULTZ, P. Investments in Women Human Capital. Chicago Press, 1995.

BATISTA, N. N.F.; CACCIAMALI, C. C. Diferencial de salários entre homens e mulheres segundo a condição de migração. Revista Brasileira de Estudos Populacionais, v. 26, n. 1, p. 97-115, jan/jun 2009.

BECKER, G. S. Human Capital: a theoritical and empirical analysis. New York: Columbia University Press, 1975.

BORJAS, G. J. Labor Economics. 3. ed. United States: McGraw Hill, 2005. 536 p.

BOWLES, S.; GINTIS, H.. The Problem with Human Capital Theory: A Marxian Critique. The American Economic Review, vol. 65, n. 2, p. 74-82, 1975.

CACCIAMALI, M. C., FERNANDES, R. Distribuição dos trabalhadores e diferenciaisde salários entre mercados de trabalho regulamentado e não regulamentado. Pesquisa e Planejamento Econômico, Rio de Janeiro, v. 23, n. 1, p. 135-156,1993.

CAMARGO, J. M.; SERRANO, F. Os dois Mercados: homens e mulheres na indústria brasileira. Texto para Discussão n. 46, PUC-Rio, 1983.

CAMBOTA, J. N.; MARINHO, E. L. L. Discriminação Como Uma das Fontes de Desigualdade de Rendimentos no Mercado de Trabalho das Regiões Nordeste e Sudeste. Economia. Brasília - DF, v. 7, n. 3, p. 597-619, 2007.

CAMERON, A. C.; TRIVEDI, P. K. Microeconometrics: Methods and Applications. New York: Cambridge University Press, 2005.

CAVALIERI, C. H.; FERNANDES, R. Diferenciais de Salário por Gênero e Cor: uma comparação entre as regiões metropolitanas brasileiras. Revista de Economia Política, v. 18, n. 1, p. 158-175, 1998.

CIRINO, J. F. ; LIMA, J. E. . Diferenças de rendimento entre as regiões metropolitanas de Belo Horizonte e Salvador: uma discussão a partir da decomposição de Oaxaca-Blinder. XLVIII Congresso Sociedade Brasileira de Economia, Administração e Sociologia Rural - SOBER, 2010, Viçosa - MG, XLVIII Congresso Sociedade Brasileira de Economia, Administração e Sociologia Rural SOBER, 2010.

COELHO, A. M.; CORSEUIL, C. H. Diferenciais Salariais no Brasil: um breve panorama. Texto para Discussão n. 898, IPEA, 2002. 
FERNANDES, R. Mercado de trabalho não-regulamentado: participação relativa e diferenciais de salários. Pesquisa e Planejamento Econômico, Rio de Janeiro, v. 26,n. 3, 1996.

FERNANDES, M. M. ; HERSKOVIC B. ; MATION, L. F. . Diferenciais salariais ao longo do ciclo da vida. In: XXXVII Encontro Nacional de Economia - ANPEC, 2009, Foz do Iguaçu. XXXVII Encontro Nacional de Economia - ANPEC, 2009.

FREISLEBEN, V. da S.; BEZERRA, F. M.. Ainda existe discriminação salarial contra as mulheres no mercado de trabalho da Região Sul do Brasil? - Evidências para os anos de 1998 e 2008. In: V Encontro de Economia Catarinense-APEC, 2011, Florianópolis. V Encontro de Economia Catarinense - APEC, 2011.

GARDNER, H. Frames of Mind: The Theory of Multiple Intelligences. New York: Basic Books. 1983.

GIUBERTI, A. C.; MENEZES-FILHO, N. Discriminação de Rendimentos por Gênero: uma comparação entre o Brasil e os Estados Unidos. Economia Aplicada, v. 93, n.3, p. 369-383, 2005.

GOLDIN, C. A pollution theory of discrimination: male and female differences in occupations and earnings. National Bureau of Economic Research, Working Paper n. 8985, 2002.

HECKMAN, J. J.. Sample Selection bias as a specification error. Econometrica, vol. 47, p. 153-162, 1979.

JANN, B. A Stata implementation of the Blinder-Oaxaca decomposition. ETH Zurich Sociology, Working Paper, Zurich, Switzerland, n. 5, may 2008.

LANGONI, C. G. (1973). Distribuição da Renda e Desenvolvimento Econômico do Brasil. Rio de Janeiro: FGV Editora. 2005.

LEME, M. C.; WAJNMAN, S. Tendências de Coorte nos Diferenciais de Rendimento por Sexo. In: HENRIQUES, R. M. (org). Desigualdade e Pobreza no Brasil. Rio de Janeiro: IPEA, 2000.

KASSOUF, A. L. The Wage Rate Estimation Using the Heckman Procedure. Revista de Econometria, n. 1, 1994.

MENEZES-FILHO, N.; PICCHETTI, P.; FERNANDES, R.. A evolução da distribuiç̧ão de salários no Brasil: fatos estilizados para as décadas de 80 e 90. In: HENRIQUES, R. M. (org.). Desigualdade e pobreza no Brasil. Rio de Janeiro: IPEA, 2000.

MINCER, J. Schooling, experience and earnings. New York: Columbia University Press, 1974. 
OAXACA, R..Male-female wage differentials in urban labor markets. International Economic Review, vol. 14, n. 3, p. 693-709, oct. 1973.

O'NEILL, J. E.; O'NEILL, D. M. What do wage differentials tell us about labor market discrimination? Research in Labor Economics, vol. 24, p. 293-357. 2005.

PSACHAROPOULOS, G. Returns to Education: A Further International Update and Implications. The Journal of Human Resources, vol. 20, n. 4, p. 583-604, Autumn, 1985.

PSACHAROPOULOS, G.; TZANNATOS, Z. Women's employment and pay in Latin America: overview and methodology. Washington D. C.: The World Bank, 1992.

QUEIROZ, V. S.; MOREIRA, I. T..Uma Análise dos Diferenciais de Renda e Discriminação no Mercado de Trabalho Brasileiro. In: VII Encontro Nacional da Associação Brasileira de Estudos Regionais e Urbanos - ENABER, 2009, São Paulo SP. VII Encontro Nacional da Associação Brasileira de Estudos Regionais e Urbanos - ENABER, 2009.

RESENDE, M.; WYLLIE, R.. Retornos para Educação no Brasil: evidências empíricas adicionais. Economia Aplicada. São Paulo, v. 10, n. 3, p. 349-365, jul.-set., 2006.

SACHSIDA, A.; LOUREIRO, P. R. A.; MENDONÇA, M. J. C. de. Um Estudo sobre Retorno em Escolaridade no Brasil. Revista Brasileira de Economia, Rio de Janeiro, v. 58, n. 2, p. 249-265, abr. - jun., 2004.

SALVATO, M. A. ; SILVA, D.G. . O impacto da Educação nos Rendimentos do Trabalhador. In: XIII Seminário sobre a Economia Mineira, 2008, Diamantina, MG. Anais do XIII Seminário sobre a Economia Mineira, 2008. Belo Horizonte, 2008.

SCHULTZ, T. W..Investment in Human Capital. The American Economic Review, vol. 51, n. 1, p. 1-17, mar., 1961.

SCORZAFAVE, L. G.; MENEZES-FILHO, N.. Participação Feminina no Mercado de Trabalho Brasileiro: evolução e determinantes. Pesquisa e Planejamento Econômico, Rio de Janeiro, v. 31, n. 3, p. 441-478, 2001.

SCORZAFAVE, L. G.; PAZELLO, E. T. Using Normalized Equations to Solve the Indetermination Problem in the Oaxaca-Blinder Decomposition: An Application to the Gender Wage Gap in Brazil. Revista Brasileira de Economia, Rio de Janeiro, v.61, n. 4, p. 535-548, 2007.

SENNA, J. Escolaridade, Experiência no Trabalho e Salários no Brasil. Revista Brasileira de Economia, Rio de Janeiro, v. 30, n. 2, 1976. 
SULIANO, D. C.; SIQUEIRA, M. L.. Um Estudo do Retorno da Educação na Região Nordeste: análise dos estados da Bahia, Ceará e Pernambuco a partir da recente queda da desigualdade. In: V Encontro de Economia do Ceará em Debate - IPECE, 2009, Fortaleza - CE. V Encontro de Economia do Ceará em Debate - IPECE, 2009.

TANNURI-PIANTO, M. E., PIANTO, D. Informal employment in Brazil - a choice at the top and segmentation at the bottom: a quantile regression approach. 2002, mimeo.

Submetido em $25 / 03 / 2013$

Aprovado em 13/12/2013

\section{Sobre os autores}

\section{Rafael Mesquita Pereira}

Mestre pela Universidade Federal de Pelotas - UFPel e Professor Assistente da Universidade Federal do Rio Grande - FURG.

Endereço para correspondência: Av. Itália, Km 8, Carreiros. 96203900 - Rio Grande, RS - Brasil

E-mail: rafaelmesquita@furg.br

\section{Cristiano Aguiar de Oliveira}

Doutor pela Universidade Federal do Rio Grande do Sul - UFRGS e Professor Adjunto da Universidade Federal do Rio Grande - FURG.

E-mail: cristiano.oliveira@furg.br 